\title{
Medical Negligence-Legal Narrative and Prevention in Malaysian Medical Practice
}

\author{
Hafizah Zainal ${ }^{1}$, Hazdalila Y. Razali ${ }^{1}$, Jesmine Khan ${ }^{2}$, Mohammed N. Islam ${ }^{2 *}$ \\ ${ }^{1}$ Ampang Hospital, Jalan Mewah Utara, 68000 Ampang Jaya Selangor, Malaysia \\ ${ }^{2}$ Faculty of Medicine,Universiti Teknologi MARA (UiTM), Jalan hospital, 47000 Sungai Buloh, Selangor, Malaysia
}

\begin{abstract}
Medical negligence cases in Malaysia are not far behind from other developed countries in terms of quantity and costs. The challenges of medical negligence in Malaysia have always been an enemy to both patients and doctors. Both parties may lose more than they gain from the adversarial adventure of medical litigation. Hence prevention of medical negligence is the best effort in ensuring the best medical practice for both parties. Practicing ethical medical practice and improving communication with the patient is some of the methods to avoid getting sued. If this fails, alternatives to medical litigation such as alternative dispute resolution in the form of mediation and no-fault compensation scheme. These alternatives may offer more to both parties rather than going through the litigation process.

Keywords: Medicolegal, Medical negligence, Medical litigation, Ethical practice, Alternative dispute resolution, Defensive medicine

Int J Eth Trauma Victimology (2020). DOI: 10.18099/ijetv.v6i02.6
\end{abstract}

\section{INTRODUCTION}

$\mathrm{T}$ he change of medical practice from medical paternalism to replacing patient's autonomy has been seen for the past few decades. Doctors can never know enough about patients to make decisions for them. Negligence in medical practice differs from other areas of tort due to medicine as an inexact science. Doctors cannot guarantee to cure patients all the time; the reasonable expectations are to provide the service with reasonable care and skill up to the acceptable standard of practice. ${ }^{1}$ The complexity of medical negligence also is because it involves the life and functional capacity of the patients.

As per Baron Alderson, ${ }^{2}$ negligence is the omission or commission to do something that a reasonable man would do or doing something which a prudent and reasonable man would not do. In law, negligence connotes the complex concept of duty, breach, and damage ${ }^{3}$ suffered by the person to whom the duty is owed, in a medical negligence case, the patient.

The problem with medical negligence compensation is that it may be unpredictable, and the success may not be due to the merits of the claims ${ }^{4}$ The outcome of a negligence case can be unpredictable. The availability and the dependability of evidence and witnesses and the quality and expertise of the legal representation are some of the reasons that the outcome can be unpredictable. ${ }^{5}$

\section{Challenges of Medical Litigation in Malaysia}

Medical practice in Malaysia has shown an increasing trend of medical negligence cases. ${ }^{4}$ Pursuing medical malpractice is proven to be challenging for both patients and doctors. The cost and lengthy-time period are difficult for both patients and
Corresponding Author: Mohammed Nasimul Islam, MBBS, PhD., 2Faculty of Medicine,Universiti Teknologi MARA (UiTM), Jalan hospital, 47000 Sungai Buloh, Selangor, Malaysia, e-mail: nasimevu@yahoo.com

How to cite this article: Zainal H, Razali HY, Khan J, Islam MN. Medical Negligence - Legal Narrative and Prevention in Malaysian Medical Practice. Int J Eth Trauma Victimology. 2020;6(2):22-25.

Source of support: Nil

Conflict of interest: None declared

Received:28/08/2020;

Received in revised form: 29/09/2020; Accepted:28/09/2020; Published:25/12/2020

doctors to bear. For example, an average for 15-25 years is taken for a case to be resolved in a Malaysian court. ${ }^{1,4,6}$

Access to the medical record is among the procedural obstacles that are faced in medical litigation cases. Although the Guideline of the Malaysian Medical Council has mentioned that the medical record is the property of practitioner's and the patient, patients still have difficulty obtaining a medical record to use as evidence in court. ${ }^{4,6}$ The process of obtaining these records would delay medical litigation duration further as the records need to be obtained through a court order.

Other than the written evidence, obtaining the expert medical witness is also a challenging element in medical litigation. Doctors may be unwilling to provide evidence against their colleagues. Plaintiff may also have difficulty in obtaining their expert witness as the doctor may be reluctant to give evidence in court. ${ }^{1,4}$

The limitation period for a medical negligence case is covered under the Malaysia Limitation Act 1953 (Act 254). This act aims to protect defendants from stale claims and encourage patients not to sit on an action when needed. ${ }^{4}$ However, in 
some medical cases, the latent injury may not have damages, which may lead to the run out of time from the cause of action to take place.

The threat of litigation also destroys the doctor-patient relationship because of the adversarial nature of medical litigation. This introduces the confrontational elements between them. ${ }^{5}$ The adversarial nature of litigation denies both parties to have adequate explanations and apologies are difficult to be given in these circumstances. The hostile environment of the court may destroy both parties' trust in each other. In some studies, litigation threat can also cause doctors to deviate from their normal practice and lead to defensive medicine.

Defensive medicine is medical care performed primarily to reduce the risk of litigation and not for the benefit of the patients. $^{7}$ The positive effect of defensive medicine is that doctors will perform more tests and procedures than necessary. However, from a negative point of view, defensive medicine leads doctors to avoid taking risks and hence avoiding treating patients. Doctors will ultimately choose a safer profession that has fewer litigations. Costs of practicing defensive medicine also are higher since more test and procedures are being done.

\section{Change of the Standard of Care in Malaysian Medical Practice}

In the court of law, the standard of care is divided into the doctor's duty to make the diagnosis, give information or advice, and provide treatment to the patient as needed. A breach in any of these care standards would satisfy the negligence elements, and the doctor is liable. The main source of medical negligence law in Malaysia derived from Section 3 of the Malaysian Civil Law Act 1956 wherein absence of written Malaysian law; the court shall apply the other Commonwealth country common law as they see fit. Thus, the medical cases from other countries especially from England have been the main reference to Malaysian medical litigation cases.

In England, the Bolam principle is based on the practice of the doctor accepted as proper by a responsible body of medical opinion skilled in that particular art. ${ }^{8}$ This principle came from a legal case, which is Mr Bolam, a mentally-ill patient who received electro-convulsion therapy without any muscle relaxant or proper restraint. Following the procedure, he suffered injury and sued the doctor.

Following this principle, the doctor would be found liable if there is another medical opinion that practice accordingly. Thus, this provides difficulty to the plaintiff patient to prove liability.

However, for the past few years, the transformation of the standard of care in Malaysian medical practice has been seen. From the Bolam principle, the medical-legal system has adopted other principles in medical litigation. ${ }^{1,6}$

In the case of Bolitho, ${ }^{9}$ the court held that the defendant doctor is not liable only if the practice can demonstrate a logical basis. The expert medical opinion has to have a sufficient basis before being accepted as responsible in court. If the expert medical opinion does not withstand the logical analysis, the judge is entitled to hold that the body of opinion is not responsible.

Australian judiciary is also quite determined in scrutinizing expert evidence. In the case of Rogers $v$ Whitaker ${ }^{10}$ where it was held that the amount of information to be disclosed to the patient cannot be determined by the doctor but it would depend on the complexity of the nature of the treatment. In this case, the court found Dr Whitaker liable for not disclosing a very rare complication of a procedure which is proven to be significant for the plaintiff, Mrs. Rogers.

Examples of earlier medical negligence cases where the Bolam rule was followed are Swamy v Mathews, ${ }^{11}$ Chin Keow $v$ Government of Malaysia and Anor, ${ }^{12}$ and Elizabeth Choo v Government of Malaysia. ${ }^{13}$ However, more recent cases have shown the impact of the Rogers case where Malaysian court had turned away from the Bolam principle. Examples of recent cases are Kamalam a/p Raman v Eastern Plantation Agency \& Anor, ${ }^{14}$ Foo Fio Na v Hospital Assunta and Anor, ${ }^{15}$ and Hong Chuan Lay v Dr Eddie Soo Fook Mun. ${ }^{16}$ In these cases, the departure from the Bolam principle is seen in cases where it involves the duty to warn or disclose risks to patients. ${ }^{17}$

\section{Prevention of Medical Litigation}

As discussed, pursuing medical litigation is challenging for both patients and doctors. If given alternatives, patients and doctors may opt for other methods to resolve the dispute. Before litigation, there are several approaches in preventing medical practice to advance to the court of law. This includes good ethical medical practice and enhancing communication with the patient.

Suppose the dispute cannot be resolved at the early stage. In that case, an alternative to medical litigation, such as alternative dispute resolution, which is mediation to help the patient and doctor to settle the dispute outside the court, must be available.

\section{Good Medical Practice}

There are many aspects of good medical practice that can be followed in order to prevent medical litigation. Detailed and explicit documentation must be enforced in order to clear any miscommunication that may ensue later. In case of litigation, good documentation is a good defence for the defendant doctor.

Informed consent is a practice which has good value in preventing medical litigation. Consent can be either expressed or implied. ${ }^{17}$ Expressed consent may be in the form of verbal or written. Informed consent consists of three important components, which are real, capacity and voluntary.

In order for consent to be legally valid, the consent needs to be real. The patient must be given sufficient information about the treatment they are about to undertake. The risks and benefits of the treatment and also alternatives to the treatment must be informed to the. Secondly, consent is only valid when the patient can give consent. Capacity is presumed in an adult with a sound mind. Children under the age of 18 in Malaysia is legally considered as not having the capacity to give consent; hence the consent should be taken from their 
parents or guardian. The third component is that consent must be voluntary from the patient's own free will with no duress or undue influence. ${ }^{17}$

Doctors need to be updated with the latest knowledge and skills. Evidence-based medicine needs to be applied to ensure that patients receive the standard of care they deserve. Doctors need to know the local policies or guidelines which applies at the place of their practice so that their practice will be in accordance with the standard among other doctors. Other than medical knowledge, they need to be aware of the medicolegal implications of their medical practice too. Knowledge of common miscommunication and medical malpractice would help in ensuring that the doctor would practice cautiously.

\section{Communication}

Poor communication is one of the commonest reasons given by patients to sue. Doctors often refuse or communicate poorly during their care of the patient. They are always in a hurry, dismissive and abrupt in their contacts with patients and family members. Patients and family members feel frustrated and angry with the lack of communication by the doctors. ${ }^{18}$ Any right treatment or even absence of any misconduct may sometimes lead to dissatisfaction from the patient due to the misunderstanding they experience.

As Malaysia is a multicultural country, communication between multilingual patients and doctors can be a challenge. Doctors should ensure enough time is spent communicating with patients and family members. They should not also leave the communication to the junior doctors or nurses to communicate on their behalf.

\section{Alternatives in Medical Negligence}

If preventing medical malpractice has failed and both patient and doctor are unable to achieve an agreement, before going to court, there may be some other alternative to resolve the dispute.

\section{Alternative Dispute Resolution}

Alternative dispute resolution (ADR) is a means to settle disputes outside of the court. The ADR may include negotiation, conciliation, mediation, and arbitration. ADR is easier and less complicated than litigation. In medical negligence, the best ADR to be applied is mediation. The application of mediation in Malaysian court was introduced in 2010 by the Federal Court in the Practice Direction No $5 .^{6}$ However, there is no specific provision for its application in medical negligence. The main objective of mediation is to provide a platform for both dispute parties to discuss peacefully to achieve mutual agreement. Mediation can help because it is more economical, fast; in most instances, the parties perceive it to be fair, minimizes the risks for parties, and the outcome is confidential. Mediation empowers the parties to understand and control the outcome of the dispute. ${ }^{6}$ Instead of waiting and agreeing with the court's decision, both parties have a chance to find an agreement for the dispute.

\section{No-fault Compensation Scheme}

Medical compensation for medical injuries can be seen as a social problem in which the compensation may not be fair. Patients who have the time and costs to be able to infiltrate the legal system are likely to be compensated more than those who have no time and money for it. Court has difficulty in quantifying the compensation to be given to the plaintiff. Similar injuries may end up with different compensation. The lump-sum payment to the plaintiff maybe inaccurate. ${ }^{5}$ In this scheme, the fault of medical malpractice is seen as distributive justice rather than individual corrective justice. ${ }^{5}$ In this system, the resources for compensation is contributed among all members of a pool, and recipients are chosen in accordance with distributive criteria. Implementing this system requires a comprehensive national social welfare which controls the resources accordingly. Patients will receive compensation when injury or damages are done upon them. By applying this scheme, the responsibility to the personal injury is accountable amongst the members of the public and not to the individual doctor.

Although the compensation may be less than what the patient may get if they win in court, the compensation from the no-fault compensation will be spent only on the patient's well-being rather than to the legal costs. It will also spare both parties from the intense emotional experience of litigation.

\section{Conclusion}

Changes in litigation in Malaysian medical practice over the past few decades is evident. The challenges that are faced by patients and doctors are the high cost, time-consuming, difficulty in accessing medical records and expert witnesses, limitation period constraints, risking doctor-patient relationship and development of defensive medicine from the advancement of medical litigation.

For these reasons, prevention of advancement of medical litigation is fundamental to ensure that the practice of medicine can develop efficiently. In preventing medical malpractice, good medical practice is necessary. Good documentation, the use of informed consent and doctors' updated knowledge and skill would be some of the criteria of good medical practice. Other than this, effective communication ensure that less misunderstanding takes place during the practice.

However, even if the misunderstanding has grown into disputes between patients and doctors, there are still some methods to prevent medical litigation from going to court. Alternative dispute resolution by means of mediation has been suggested to be reasonable to be done to resolve a medical dispute. Another method is the no-fault scheme, which gives compensation to patients controlled by a comprehensive national social welfare. The resources would come from a pool contributed by the doctors.

Although all these preventions may have their own struggle to be implemented, doctors should always bear in mind that each and every one of medical practitioners plays a part in the overall prevention of medical negligence. Assistance and 
support from the employer and the stakeholders in ensuring that the medical practice would not get through the litigation are also eminent.

\section{REFERENCES}

1. Jahn Kassim P. Medical Negligence Law in Malaysia. 2nd ed. Selangor: International Law Book Services; 2003.

2. Blyth v Birmingham Waterworks Co. 1856.

3. Lochgelly Iron and Coal Co v McMullan.

4. Hambali SN, Khodapanahandeh S. Review of medical malpractice issues in Malaysia under tort litigation system. Glob J Health Sci. 2014;6(4):76.

5. Kassim PNJ, Najid KM. Medical negligence disputes in Malaysia: resolving through hazards of litigation or through community responsibilities? In: Proceedings of World Academy of Science, Engineering and Technology. Citeseer; 2013. p1607.

6. Mokhtar MFM. Medical Negligence Dispute in Malaysia: Choosing Mediation as the Best Constructive Approach to Address the Paradoxes in Medical Negligence Claims. Eur J Interdiscip Stud. 2016;2(2):202-211.
7. Bishop TF, Pesko M. Does defensive medicine protect doctors against malpractice claims? British Medical Journal Publishing Group; 2015.

8. Bolam v Friern Hospital Management Committee. 1957.

9. Bolitho v City \& Hackney Health Authority. 1997.

10. Rogers v Whitaker. 1993.

11. Swamy v Mathews. 1968

12. Chin Keow v Government of Malaysia \& Anor. Vol. 45, MLJ. 1967.

13. Elizabeth Choo v Government of Malaysia. Vol. 171, MLJ. 1970.

14. Kamalam a/p Raman v Eastern Plantation Agency \& Anor. Vol. 674, MLJ. 1996.

15. Foo Fio Na v Hospital Assunta \& Anor. Vol. 738, MLJ. 1999.

16. Hong Chuan Lay v Dr Eddie Soo Fook Mun. Vol. 251, CLJ. 1998.

17. Jahn Kassim P. Law and Ethics relating to Medical Profession. 1st ed. Kuala Lumpur: International Law Book Services; 2007.

18. Academy of Medicine of Malaysia (AMM) - Ethical Professional Practice Guidelines AMM 2016 [Internet]. [cited 2020 Dec 12]. Available from: http://www.acadmed.org.my/index. cfm?\&menuid=131 